\title{
Phytochemical screening and allelopathic evaluation of aqueous and methanolic leaf extracts of Populus nigra L.
}

Naila Inayat ${ }^{1}$, Zahir Muhammad $^{1 *}$, Rehmanullah $^{1}$ and Abdul Majeed ${ }^{2}$

1. Department of Botany, University of Peshawar, Peshawar, Khyber Pakhtunkhwa-Pakistan

2. Department of Botany, Govt. Degree College Pabbi Nowshera, Khyber Pakhtunkhwa-Pakistan

*Corresponding author's email: kzahirmuhammad@yahoo.com

Citation

Naila Inayat, Zahir Muhammad, Rehmanullah and Abdul Majeed. Phytochemical screening and allelopathic evaluation of aqueous and methanolic leaf extracts of Populus nigra L. Pure and Applied Biology. Vol. 9, Issue 1, pp1242-1249. http://dx.doi.org/10.19045/bspab.2020.90100

\begin{tabular}{llll}
\hline Received: 09/07/2019 & Revised: 19/10/2019 & Accepted: 30/11/2019 & Online First: 10/01/2020 \\
\hline \hline
\end{tabular}

\section{Abstract}

Allelopathic compounds are secondary metabolites which are produced during different metabolic pathways and apparently they have no prominent role in plants' growth and development. However, these compounds are supposed to play an important role in defense and interactions of producers with receivers. In this study, aqueous and methanolic leaf extracts of Populus nigra were screened for the presence of secondary metabolites and tested for the allelopathic effects on seed germination of four wheat cultivars (Ghazanvi, Siran, Atta Habib and Janbaz). Phytochemical screening revealed the presence of alkaloids, flavonoids, steroids, terpenoids, saponins, tannins, phlobatanins, and glycoside, reducing sugars, triterpenes, phytosterols and proteins in leaf extracts. Allelopathic bioassay demonstrated that leaf extracts had detrimental influence on the seed germination of four cultivars of wheat, which depended on the amount of powder dissolved in extracts $(10,20,40$ and $80 \mathrm{~g})$. Methanolic extracts exhibited greater degree of phytotoxicity than aqueous leaf extracts. Among the tested cultivars, Janbaz and Ghaznavi were more sensitive to aqueous and methanolic extracts particularly at the highest dose of concentration $(80 \mathrm{~g})$. The study suggests the presence of wide range of bioactive compounds in $P$. nigra leaves with phytotoxic potentials on wheat germination.

Keywords: Allelopathy; Alkaloids; Inhibitory effect; Secondary metabolites; Wheat

\section{Introduction}

Allelopathy is an important biological phenomenon which is directed by the releases of biological molecules from different plant parts in the form of rootexudates, leachates from above ground parts, volatilization or decomposed residues to interact with other plants, microbes and other organisms for either beneficial or negative association $[1,2]$. The process is intricate in nature which may be due to the interaction of various groups of chemical compounds like alkaloids, flavonoids, phenolics, glycosides, lactones, quinines, volatile terpenes, organic acids compounds and other secondary metabolites (allelochemicals) -which are produced during secondary metabolic pathways and apparently have no active role in growth and development of plants but are concerned with defense and interaction with other organisms [3, 4]. Usually, the allelopathic effect of one plant on the other is 
perceived to be due to the synergetic or antagonistic effects of different compounds in order to make the environment conducive for allelopathic plants [5].

In many countries including Pakistan, wheat is grown close to poplar (Populus nigra) -a multipurpose tree of significant economic importance. However, the leaves of these trees might release toxic compounds when they fall and undergo decay process in the soil. This is a common problem but the underline mechanism is not fully understood. A number of researchers assessed the allelopathic effects of different Poplar species on agricultural crops which include Populus deltoides [6-8], Populus tomentosa [9], and Populus euphratica [10]. However, research is lacking in review on phytochemical screening and allelopathic effects of $P$. nigra on wheat. Thus understanding of the allelopathic nature of Populus leaves, their phytochemical screening and effects on wheat are crucially needed for possible crop modification pattern in an agro-farming system where populous trees are cultivated. The aim of the present work was therefore to carryout phytochemical screening of aqueous and methanolic leaf extracts of P. nigra and to test them on germination of wheat.

\section{Materials and methods Extraction and fractionation}

Leaves of $P$. nigra were collected from District Charsadda in October 2014; washed with running tap water for removing the surface contaminants and dust, then dried at room temperature for two weeks in shade, and was crushed using electric blender. The leaf powder $(800 \mathrm{~g})$ was extracted by soaking it in fresh water and methanol at room temperature separately. The extracts were then filtered and concentrated by Rotavapor under reduced pressure at temperature below $50^{\circ} \mathrm{C}$. The final residue obtained was weighed $(15.2 \mathrm{~g})$ in fresh water and $(21.1 \mathrm{~g})$ in methanol. Each of the extract was screened for the presence of phytochemicals as per the standard procedures [11]. The aqueous extract $(210 \mathrm{~g})$ was subjected to fractionation and was partitioned successively with nhexane, ethyl acetate, chloroform and methanol. Each extract was evaporated to dryness under reduced pressure that yielded ethyl acetate $(7 \mathrm{~g})$, chloroform (5 g) and methanol fraction $(20 \mathrm{~g})$ respectively. However, no n-hexane fraction was obtained.

\section{Phytochemical Screening}

Crude extracts of $P$. nigra including hot water and tap water and methanolas well as their sub-fractions were screened for qualitative determination of various secondary metabolites according to standard analytical methods [12].

\section{Test for reducing sugars}

To the extracts in separate test tubes 3-4 drops Fehling's solution was added and heated. The appearance of red color revealed reducing sugar was present.

\section{Steroids}

$2 \mathrm{ml}$ of acetic anhydride and $2 \mathrm{ml}$ concentrated $\mathrm{H}_{2} \mathrm{SO}_{4}$ were added to $5 \mathrm{ml}$ of the extracts in separate test tubes. Change of color from violet to blue confirmed the presence of steroids.

\section{Glycosides}

$2 \mathrm{ml}$ of glacial acetic acid containing 1 drop of ferric chloride solution and $1 \mathrm{ml}$ of concentrated $\mathrm{H}_{2} \mathrm{SO}_{4}$ were added to $4 \mathrm{ml}$ of extracts. Appearance of a brown ring indicated the presence of glycosides.

\section{Tannins test}

Crude extracts $(0.5 \mathrm{~g})$ were suspended in water and heated on water bath and filtered, followed by adding few drops of ferric chloride to the filtrates. The appearance of green color indicated the presence of tannins.

\section{Alkaloids test}

Crude extracts $(0.5 \mathrm{~g})$ were warmed with $5 \mathrm{ml}$ of $2 \% \mathrm{H}_{2} \mathrm{SO}_{4}$ for 2 minutes, filtered and 2-3 drops of Dragendrof's reagent was added to each filtrate and observed for red precipitation. 


\section{Saponins test}

Crude extracts $(0.5 \mathrm{~g})$ were shaken with $5 \mathrm{ml}$ of distilled water and was heated to boiling. Formation of froth with persistence time of 5 minutes or more represent saponins.

\section{Triterpenes and phytosterols test}

To $5 \mathrm{ml}$ extracts $2 \mathrm{ml}$ chloroform was added and filtered. To this filtrate $3 \mathrm{ml}$ concentrated $\mathrm{H}_{2} \mathrm{SO}_{4}$ was added, shaken and allowed to stand and observed for golden yellow color that's indicate triterpenes, while red color in the lower layer represent phytosterols.

\section{Flavonoids test}

Crude extracts $(0.5 \mathrm{~g})$ were dissolved in $1 \mathrm{ml}$ diluted $\mathrm{NaOH}$ and 3-4 drops $\mathrm{HCl}$ was added. Yellow color that turns colorless indicates the presence of flavonoids.

\section{Anthraquinones test}

Crude extracts $(0.5 \mathrm{~g})$ were boiled with $5 \mathrm{ml}$ $10 \% \mathrm{HCl}$ for few minutes in water bath, filtered and allowed to cool. To the filtrate 3 $\mathrm{ml} \mathrm{CHCl}_{3}$ was added. 2-3 drops of $10 \%$ ammonia was added to the mixtures and heated. Formation of rose-pink color indicated the presence of anthraquinones.

\section{Phlobatanins test}

Crude extracts $(0.5 \mathrm{~g})$ were dissolved in $5 \mathrm{ml}$ distilled water and filtered. The filtrate was boiled with $1 \mathrm{ml}$ of $2 \% \mathrm{HCl}$ solution. Formation of precipitation shows the presence of phlobatanins.

\section{Terpenoids test}

Crude extracts $(0.5 \mathrm{~g})$ were mixed with $2 \mathrm{ml}$ of chloroform and concentrated $\mathrm{H}_{2} \mathrm{SO}_{4}(3 \mathrm{ml})$ was carefully added to form a layer. The formation of a reddish brown coloration at the interface indicated positive results for the presence of terpenoids.

\section{Seed bioassay}

Allelopathic bioassay for seed germination of four wheat cultivars was performed at Botany Department. 10 seeds of each wheat cultivar were placed on filter paper in sterilized petri dishes. $5 \mathrm{ml}$ of each aqueous and methanolic extracts at 10, 20, 40 and $80 \mathrm{~g}$ were applied to petri dishes which were arranged in a completely randomized design. Distilled water was used as control treatment. For each treatment, five replicates of petri dishes were used. Germination \% was calculated in each treatment at $10^{\text {th }}$ day of the onset of germination bioassay. Least significant difference test was used to record the effect of extracts on germination $\%$ of wheat cultivars.

\section{Results}

Phytochemical evaluation of the aqueous leaf extracts of $P$. nigra revealed that secondary metabolites such as phenols, alkaloids, flavonoids, steroids, terpenoids, saponins, tannins, glycoside, reducing sugars, triterpenes and phytosterols were present in the samples. In methanolic extracts glycoside, reducing sugars and phytosterols were not detected while other compounds were present (Table 1). Furthermore, the organic fractions such as chloroform, ethyl acetate and methanol showed differential indication for the tested phytochemicals (Table 2).

Germination bioassay demonstrated that four varieties of wheat differed in their response to the applied extracts; showing decline at increasing concentration of extracts (Fig. 1). In aqueous extract treatments, lowest germination percentage $(28 \%)$ in cultivars Siran and Atahabib respectively at $80 \mathrm{~g}$ extract concentration was observed, which was significantly lower than control i.e., 68 and $70 \%$ respectively. In cultivar Ghaznavi, $34 \%$ germination was observed at $80 \mathrm{~g}$ extract against $64 \%$ in control. Cultivar Janbaz revealed $31 \%$ germination at $80 \mathrm{~g}$ when compared to control where it was $64 \%$. All the extract concentrations showed inhibitory effects on germination of four wheat varieties; however, highest concentration (80 g) was more phytotoxic. 
Table 1. Phytochemical screening of the crude extracts Populus nigra leaves; present (+), absent (-)

\begin{tabular}{|c|c|c|}
\hline Chemical components & Methanol extracts & Aqueous extracts \\
\hline Alkaloids & + & + \\
\hline Steroids & + & + \\
\hline Terpenoids & + & + \\
\hline Flavonides & + & - \\
\hline Anthraquinones & - & + \\
\hline Tannins & + & + \\
\hline Phlobatanins & + & + \\
\hline Saponins & + & + \\
\hline Glycoside & - & + \\
\hline Reducing sugars & - & + \\
\hline Triterpenes & + & + \\
\hline Phytosterols & - & + \\
\hline Phenol & + & + \\
\hline Proteins & + & + \\
\hline
\end{tabular}

Table 2. Phytochemical screening of aqueous extract organic fractions of Populus nigra leaves; present (+), absent (-)

\begin{tabular}{|c|c|c|c|}
\hline Chemical components & Chloroform (2 g) & Ethyl acetate (3 g) & Methanol (10 g) \\
\hline Alkaloids & - & - & + \\
\hline Steroids & + & + & + \\
\hline Terpenoids & + & + & + \\
\hline Flavonides & + & - & - \\
\hline Anthraquinones & - & - & + \\
\hline Tannins & + & - & + \\
\hline Phlobatanins & - & - & + \\
\hline Saponins & - & + & + \\
\hline Glycoside & + & + & + \\
\hline Reducing sugars & + & + & + \\
\hline Triterpenes & + & + & + \\
\hline Phytosterols & + & + & + \\
\hline Phenol & + & - & \\
\hline Proteins & - & & \\
\hline
\end{tabular}


Effect of methanolic extracts on seed germination of four cultivars of wheat is presented in (Fig. 2). Results revealed that all the extract concentrations were strongly phytotoxic which significantly lowered germination parentage in all the cultivars (or varieties?); however, unlike to aqueous extracts, $40 \mathrm{~g}$ extract concentration was more drastic in effects than other concentrations in methanolic extract. In cultivar Ghaznavi, lowest germination (12\%) was observed at 40 $\mathrm{g}$ when compared to control (64\%).
Germination was $18 \%$ at 80 g extracts. Similar tendency was recorded in cultivar Janbaz where germination was significantly lowered to $14 \%$ by $40 \mathrm{~g}$ extract concentration. Cultivar Siran was found most susceptible to the allelopathic stress at $40 \mathrm{~g}$ where only $10 \%$ seeds germinated while in Atahabib germination percentage was $20 \%$. In general, methanolic extracts were found to be more inhibitory than aqueous extracts towards seed germination of wheat.

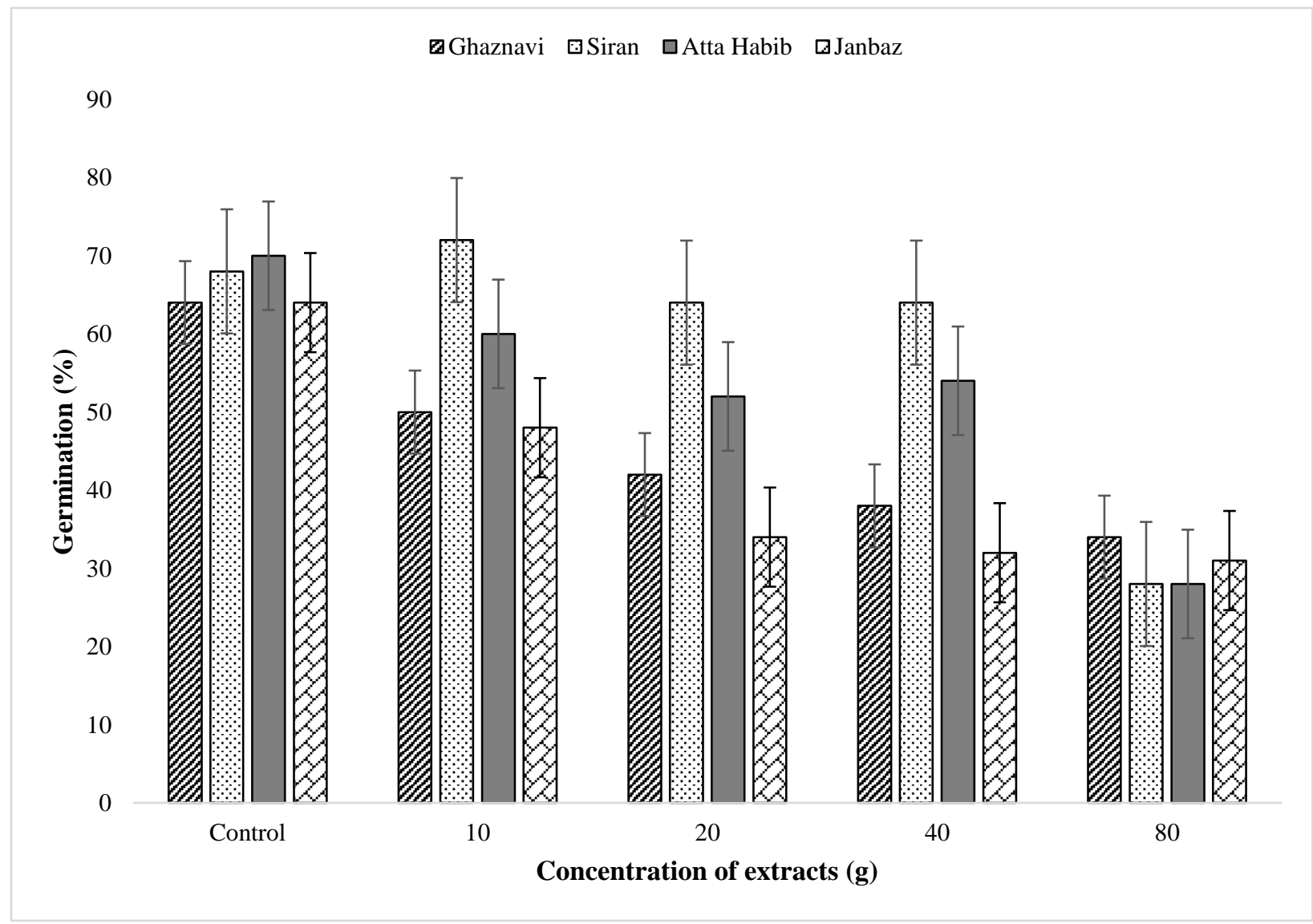

Figure 1. Effect of different concentrations of aqueous leaf extracts of $P$. nigra on seed germination $(\%)$ of four wheat varieties 


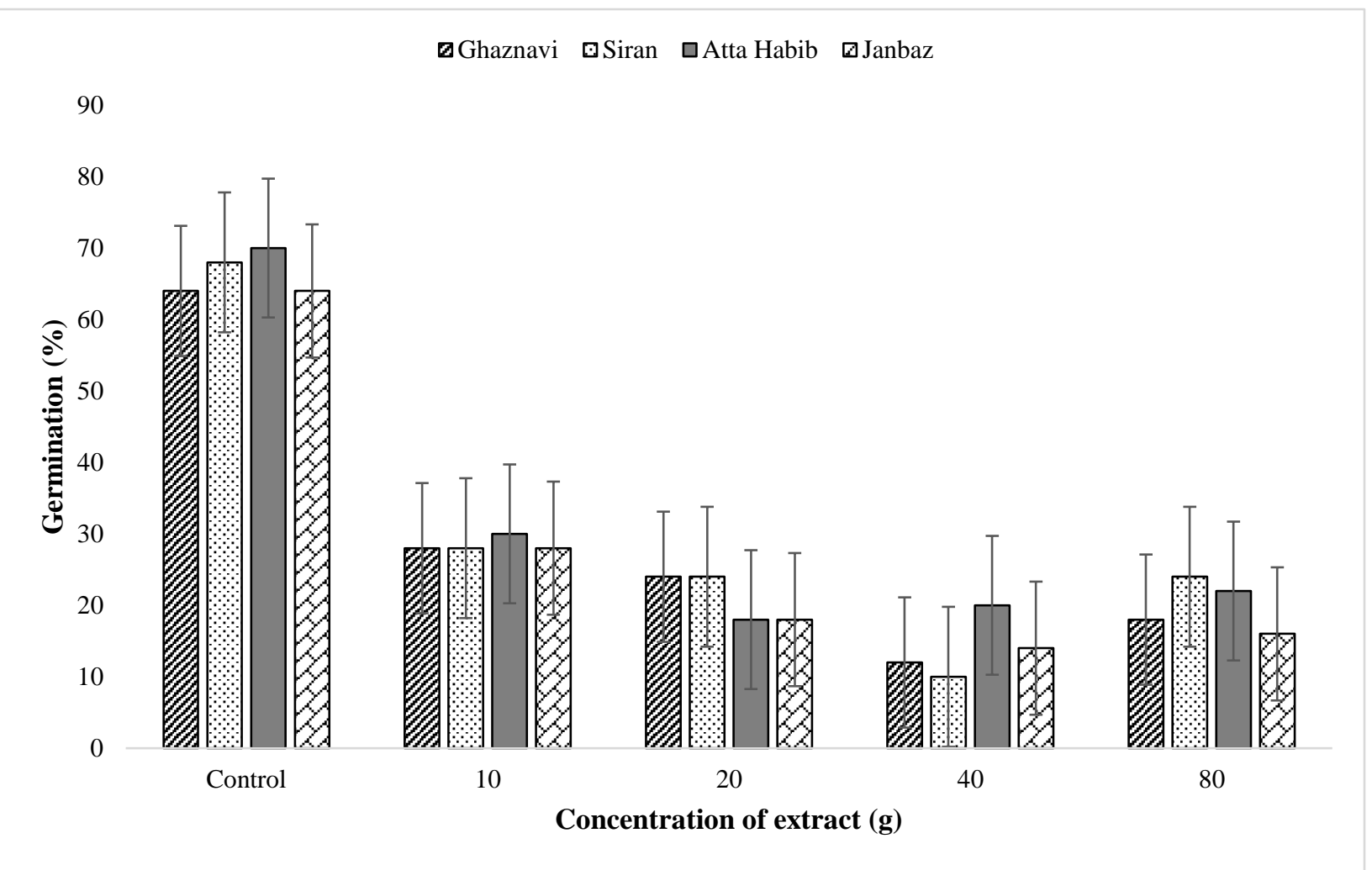

Figure 2. Effect of different concentrations of methanolic leaf extracts of $P$. nigra on seed germination $(\%)$ of four wheat varieties

\section{Discussion}

Our results regarding phytochemical screening accede with findings of those reported by Kaur and Arora [12] and Yadav and Agarwala [13] which documented different phyto-constituents in aqueous and organic-fractions extracts of different plants. Moreover, significantly lower germination of wheat cultivars in both aqueous and methanolic extracts may be attributed to the presence of phytotoxic chemicals as we identified the presence of phenols, alkaloids, tannins, glycosides, reducing sugar, saponins, carbohydrates, steroids, terpenoids, reducing sugars, triterpenes, phytosterols, and proteins in sample extracts. The differences in phytotoxicity under aqueous and methanolic extracts might be due to the release of more quantity or more types of phytotoxins or both. Alleopathy (inhibitory) potential may vary in relation to the change in polarity index of solvents i.e. methanol fraction was more phytotoxic as compared to chloroform and ethyl acetate fraction. This might be due to the nature of the organic chemical used accounting for qualitative and quantitative differences in extracted phytotoxins in different fractions.

The allelochemicals investigated in the extracts can affect physiological functions such as seed germination, respiration, photosynthesis, ion uptake, enzyme activity, water status, transpiration, stomatal opening, hormone levels $[2,14,15]$. Furthermore, they can affect cell division and differentiation, signal transduction, gene expression and cell membrane and wall structure and permeability [1]. Allelochemicals can also provoke the production of reactive oxygen species which can disturb the metabolic activities of targeted plants [16]. Presence of phenolic compounds might interfere with the 
activities of respiratory enzymes in seed germination thus causing inhibitory effect on its germination. Enzymes that mostly affected by phenolic compounds are aldolase and glucosephosphate isomerase, involved in glycolysis and glucose 6-phosphate dehydrogenase, an enzyme involved in the first step of oxidative pentose phosphate pathway [17]. Our results generally agree with previous studies conducted on the allelopathic activities of several plants on wheat germination and growth $[18,19]$.

\section{Conclusion}

The present study suggests that $P$. nigra is an allelopathic plant, which is capable of suppressing the germination of tested wheat cultivars. $P$. nigra leaves crude extracts contain different bioactive compounds e.g., alkaloids, flavonoids, steroids, terpenoids, saponins, tannins, phlobatanins, and glycoside, reducing sugars, triterpenes, phytosterols and proteins which might be responsible for its allelopathy effects.

\section{Authors' contributions}

Conceived and designed the experiments: $\mathrm{N}$ Inayat \& $\mathrm{Z}$ Muhammad, Performed the experiments: N Inayat, Analyzed the data: Rehmanullah \& A Majeed, Contributed reagents/ materials/ analysis tools: $\mathrm{Z}$ Muhammad, Wrote the paper: $N$ Inayat \& $\mathrm{Z}$ Muhammad.

\section{Acknowledgements}

This paper is part of Ph.D. thesis of Ms. Naila Inayat as partial fulfillment for the requirements of the degree of Doctor in Philosophy (PhD), submitted to the Department of Botany, University of Peshawar.

\section{References}

1. Chon SU \& Nelson CJ (2010). Allelopathy in Compositae plants. A review. Agron Sust Develop 30(2): 349358.

2. Latif S, Chiapusio G \& Weston LA (2017). Allelopathy and the role of allelochemicals in plant defense. In:
Advances in Botanical Research, Academic Press. pp 19-54.

3. Qian $\mathrm{H}, \mathrm{Xu}$ J, Lu T, Zhang Q, Qu Q, Yang Z, \& Pan X (2018). Responses of unicellular alga Chlorella pyrenoidosa to allelochemical linoleic acid. Sci Total Environ 625: 1415-1422.

4. Li S, Wang P, Yuan W, Su Z \& Bullard SH (2016). Endocidal regulation of secondary metabolites in the producing organisms. Sci Rep 6: 29315.

5. Majeed A, Muhammad Z, Hussain M \& Ahmad H (2017). In vitro allelopathic effect of aqueous extracts of sugarcane on germination parameters of wheat. Acta Agric Sloven 109(2): 349-356.

6. Sharma NK, Samra JS \& Singh PH (2000). Effect of aqueous extracts of Populus deltoides on germination and seedling growth. 1. Wheat. Allelopathy $J$ 7(1): 56-68.

7. Singh HP, Batish DR \& Kohli RK (2001). Allelopathy in agroecosystems: an overview. J Crop Prod 4(2): 1-41.

8. Masoodi TH, Islam MA, Wani M, Mir SA \& Gangoo SA (2014). Allelopathic effect of Populus deltoides and Ulmus wallichiana on biochemical constituents of maize, bean and sunflower. Karnataka J Agric Sci 26(2): 265-267.

9. Zhu M, Wang Y, Liu B, Zhang L, Wang H, Yuan Y \& Du K (2009). Effects of aqueous leaf extracts of Populus tomentosa at different ages on the growth and photosynthetic characteristics of its own seedlings. Front Agric China 3(2): 178-185.

10. Zhao S, Li J, WangY, Cheng CL \& Li JQ (2014). Effects of herbivory and defoliation on foliar phenolic compounds in Populus euphratica in the Ejina Oasis, Inner Mongolia, China. Allelopathy J 34(1): 49-57.

11. Ghasemzadeh A, Jaafar H, Baghdadi A \& Tayebi-Meigooni A (2018). Alphamangostin-rich extracts from 
mangosteen pericarp: Optimization of green extraction protocol and evaluation of biological activity. Molecules 23(8): 1852.

12. Kaur GJ \& Arora DS (2009). Antibacterial and phytochemical screening of Anethum graveolens, Foeniculum vulgare and Trachyspermum ammi. BMC Compl Alternat Med 9(1): 30-41.

13. Yadav RNS \& Agarwala M (2011). Phytochemical analysis of some medicinal plants. J Phytol 3(12).

14. Majeed A, Chaudhry Z \& Muhammad Z (2012). Allelopathic assessment of fresh aqueous extracts of Chenopodium album L. for growth and yield of wheat (Triticum aestivum L.). Pak J Bot 44(1): 165-167.

15. Jabran K (2017). Allelopathy: Introduction and Concepts. In: Manipulation of Allelopathic Crops for Weed Control. Springer, Cham. pp. 112.
16. Weir TL, Park SW \& Vivanco JM (2004). Biochemical and physiological mechanisms mediated by allelochemicals. Curr Opin Plant Biol 7: 472-479.

17. Muscolo A, Panuccio MR \& Sidari M (2001). The effect of phenols on respiratory enzymes in seed germination respiratory enzyme activities during germination of Pinus laricio seeds treated with phenols. Plant Growth Regulat 35: 31-35.

18. Muhammad Z \& Majeed A (2014). Allelopathic effects of aqueous extracts of sunflower on wheat (Triticum aestivum L.) and maize (Zea mays L.). Pak J Bot 46(5): 1715-1718.

19. Siyar S, Majeed A, Muhammad Z, Ali H \& Inayat N (2019). Allelopathic effect of aqueous extracts of three weed species on the growth and leaf chlorophyll content of bread wheat. Acta Ecol Sin 39(1): 63-68. 